\title{
Structures and Spectroscopy Studies of Two M(II)-Phosphonate Coordination Polymers Based on Alkaline Earth Metals ( $M=$ Ba, Mg)
}

\author{
Kui-Rong Ma, ${ }^{1}$ Chun-Li Wei, ${ }^{2}$ Yu Zhang, ${ }^{1}$ Yu-He Kan, ${ }^{1}$ Ming-Hui Cong, ${ }^{1}$ and Xiao-Jing Yang' \\ ${ }^{1}$ Jiangsu Key Laboratory for Chemistry of Low-Dimensional Materials, School of Chemistry and Chemical Engineering, \\ Huaiyin Normal University, Huaian 223300, China \\ ${ }^{2}$ Department of Criminal Science and Technology, Jilin Police College, Changchun 130117, China
}

Correspondence should be addressed to Kui-Rong Ma; kuirongma@163.com

Received 29 June 2012; Revised 6 September 2012; Accepted 14 September 2012

Academic Editor: Xuezhong Du

Copyright (C) 2013 Kui-Rong Ma et al. This is an open access article distributed under the Creative Commons Attribution License, which permits unrestricted use, distribution, and reproduction in any medium, provided the original work is properly cited.

\begin{abstract}
The two examples of alkaline-earth $\mathrm{M}(\mathrm{II})$-phosphonate coordination polymers, $\left[\mathrm{Ba}_{2}(\mathrm{~L})\left(\mathrm{H}_{2} \mathrm{O}\right)_{9}\right] \cdot 3 \mathrm{H}_{2} \mathrm{O}(\mathbf{1})$ and $\left[\mathrm{Mg}{ }_{1.5}\left(\mathrm{H}_{2} \mathrm{O}\right)_{9}\right] \cdot(\mathrm{L}$ $\left.\mathrm{H}_{2}\right)_{1.5} \cdot 6 \mathrm{H}_{2} \mathrm{O}$ (2) $\left(\mathrm{H}_{4} \mathrm{~L}=\mathrm{H}_{2} \mathrm{O}_{3} \mathrm{PCH}_{2} \mathrm{~N}_{2}\left(\mathrm{C}_{4} \mathrm{H}_{8}\right) \mathrm{NCH}_{2} \mathrm{PO}_{3} \mathrm{H}_{2}\right)$, N, $N^{\prime}$-piperazinebis(methylenephosphonic acid), (L- $\mathrm{H}_{2}=$ $\left.\mathrm{O}_{3} \mathrm{PH}_{2} \mathrm{CHN}\left(\mathrm{C}_{4} \mathrm{H}_{8}\right) \mathrm{NHCH}_{2} \mathrm{PO}_{3}\right)$ have been hydrothermally synthesized and characterized by elemental analysis, FT-IR, PXRD, TG-DSC, and single-crystal X-ray diffraction. Compound 1 possesses a 2D inorganic-organic alternate arrangement layer structure built from 1D inorganic chains through the piperazine bridge, in which the ligand $\mathrm{L}^{-4}$ shows two types of coordination modes reported rarely at the same time. In 1, both crystallographic distinct $\mathrm{Ba}(1)$ and $\mathrm{Ba}(2)$ ions adopt 8-coordination two caps and 9-coordination three caps triangular prism geometry structures, respectively. Compound 2 possesses a zero-dimensional mononuclear structure with two crystallographic distinct $\mathrm{Mg}(\mathrm{II})$ ions. Free metal cations $\left[\mathrm{MgO}_{6}\right]_{n}^{2+}$ and uncoordinated anions $\left(\mathrm{L}-\mathrm{H}_{2}\right)_{n}^{2-}$ are joined together by static electric force. Results of photoluminescent measurement indicate three main emission bands centered at $300 \mathrm{~nm}, 378.5 \mathrm{~nm}$, and $433 \mathrm{~nm}$ for 1 and $302 \mathrm{~nm}, 378 \mathrm{~nm}$, and $434.5 \mathrm{~nm}$ for $2\left(\lambda_{\mathrm{ex}}=235 \mathrm{~nm}\right)$, respectively. The high energy emissions could be derived from the intraligand $\pi^{*}-n$ transition stations of $\mathrm{H}_{4} \mathrm{~L}\left(310 \mathrm{~nm}\right.$ and $\left.382 \mathrm{~nm}, \lambda_{\mathrm{ex}}=235 \mathrm{~nm}\right)$, while the low energy emission ( $>400 \mathrm{~nm}$ ) of $\mathbf{1 - 2}$ may be due to the coordination effect with metal(II) ions.
\end{abstract}

\section{Introduction}

The design and synthesis of coordination polymers (CPs) based on phosphonates have always been the most important part of the work for the researchers. This is not only due to their complicated structural diversity but also their potential applications in optics, catalysis, magnetism, molecular sensing and separation, gas adsorption, and molecular recognition [1-4]. The choice of functionalized organic skeleton is the first important task in the construction of phosphonate CPs. The ligand $\mathrm{H}_{4} \mathrm{~L}$, as a type of multidentate ligand ( $\mathrm{O}$ - and/or $\mathrm{N}$-donor), can be protonated and/or deprotonated to produce $\mathrm{H}_{3} \mathrm{~L}^{-}, \mathrm{H}_{2} \mathrm{~L}^{2-}, \mathrm{HL}^{3-}$, and $\mathrm{L}^{4-}$ with versatile metal-binding and hydrogen-bonding capabilities. Most of its associated works have focused on the assembly of the transition metals, $d^{10}$-block metals, and lanthanides metal-organic open frameworks [5-14]. The other important task is the choice of metal ion in the formation of CPs. Alkaline-earth metals are reasonably good candidates due to their variable stereochemical activity, flexible coordination environment, cheaper prices, and low toxicity. A series of alkaline-earth coordination compounds with novel structures and properties have been reported [15-18]. Despite many obvious advantages, some shortcomings of itself, such as the tendency of forming solvated species and their unpredictable coordination numbers, are keeping them weighted down. Therefore, our research has focused on the synthesis and photoluminescence of phosphonate CPs based on alkaline-earth metals. We hope to get further information on structures and properties of the alkaline-earth phosphonate CPs. The study on them with the ligand $\mathrm{H}_{4} \mathrm{~L}$ has rarely been reported up to now [8]. We previously reported the 


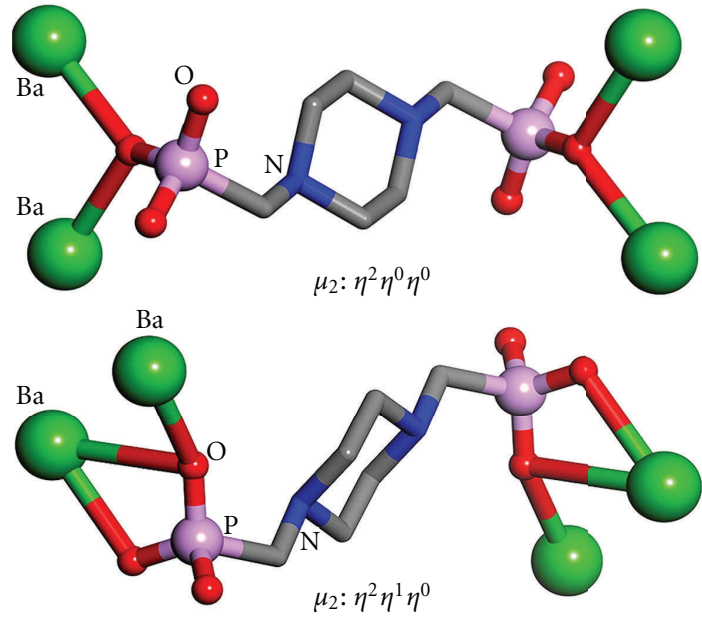

SCHEME 1: The coordination modes of the ligand $\mathrm{L}^{4-}$ in $\mathbf{1}$.

work of two compounds of $2 \mathrm{D}\left[\mathrm{Pb}_{2}(\mathrm{HL})\right] \cdot\left(\mathrm{NO}_{3}\right) \cdot 2\left(\mathrm{H}_{2} \mathrm{O}\right)$ [13] and $3 \mathrm{D}\left[\mathrm{Ba}_{3}(\mathrm{btc})_{2}\left(\mathrm{H}_{2} \mathrm{O}\right)_{4}\right] \cdot 0.5 \mathrm{H}_{2} \mathrm{O}[17]\left(\mathrm{H}_{3} \mathrm{btc}=1,3,5-\right.$ benzenetricarboxylic acid) and that we have gained a great deal of skills and experiences from this work. Herein, we discuss the structures of the two alkaline-earth $\mathrm{M}$ (II) phosphonate CPs, namely, $\left[\mathrm{Ba}_{2}(\mathrm{~L})\left(\mathrm{H}_{2} \mathrm{O}\right)_{9}\right] \cdot 3 \mathrm{H}_{2} \mathrm{O}$ (1) and $\left[\mathrm{Mg}_{1.5}\left(\mathrm{H}_{2} \mathrm{O}\right)_{9}\right] \cdot\left(\mathrm{L}-\mathrm{H}_{2}\right)_{1.5} \cdot 6 \mathrm{H}_{2} \mathrm{O}(2)$, along with their fluorescent properties.

\section{Experimental}

2.1. Materials and General Methods. N,N'-piperazinebis(methylenephosphonic acid) $\left(\mathrm{H}_{4} \mathrm{~L}\right)$ was synthesized according to the literature's methods $[19,20]$. All other chemical reagents were obtained from commercial sources and used without further purification. The elemental analysis was conducted on a Perkin-Elmer 2400 LC II elemental analyzer. IR spectrum was carried out on a Nicolet Impact 410 FI-IR spectrometer with $\mathrm{KBr}$ pellets in the $400 \mathrm{~cm}^{-1}-4000 \mathrm{~cm}^{-1}$ region. UV-Vis spectrum was carried out on a UV-3600 UV-Vis-NIR spectrophotometer by SHIMADZU with $\mathrm{BaSO}_{4}$ pellets in the $200 \mathrm{~nm}-800 \mathrm{~nm}$ region. Thermal analysis (TG-DSC) was performed on a STA 449 F3 Jupiter analyzer by NETZSCH Co., of Germany in $\mathrm{N}_{2}$ environment at a heating rate of $10 \mathrm{~K} \cdot \mathrm{min}^{-1}$. Emission and excitation spectra were recorded on a PerkinElmer LS 55 fluorescence spectrometer. The powder X-ray diffraction (PXRD) pattern was collected on an ARL X'TRA diffractometer using graphite-monochromated $\mathrm{Cu} \mathrm{K} \alpha$ radiation $(\lambda=1.5418 \AA)$ in the angular range $2 \theta=4^{\circ}-40^{\circ}$ with stepping size of $0.02^{\circ}$ and counting time of $4 \mathrm{~s}$ per step.

2.2. The Preparation of $\left[\mathrm{Ba}_{2}(\mathrm{~L})\left(\mathrm{H}_{2} \mathrm{O}\right)_{9}\right] \cdot 3 \mathrm{H}_{2} \mathrm{O}$ 1. A mixture of $0.53 \mathrm{~g}(2.0 \mathrm{mmol}) \mathrm{BaCl}_{2} \cdot 2 \mathrm{H}_{2} \mathrm{O}, 0.11 \mathrm{~g}(0.4 \mathrm{mmol}) \mathrm{H}_{4} \mathrm{~L}$, $0.06 \mathrm{~g}(0.4 \mathrm{mmol}) 4,4^{\prime}$-bipyridine, and $10.0 \mathrm{~mL}(555 \mathrm{mmol})$ deionized water was sealed in a $23 \mathrm{~mL}$ Teflon-lined stainless steel autoclave, and then heated at $160^{\circ} \mathrm{C}$ for $120 \mathrm{~h}$. The crystals of (1) (colorless block shaped) were collected by vacuum filtration, washed thoroughly with deionized water and dried in air (yield $81 \%$ based on barium atom). Elemental analysis, $\mathrm{C}_{6} \mathrm{H}_{36} \mathrm{Ba}_{2} \mathrm{~N}_{2} \mathrm{O}_{18} \mathrm{P}_{2}$ : C 9.54, $\mathrm{H}$ 4.86, $\mathrm{N}$ 3.81. Calcd.: C 9.46, H 4.73, N 3.68\%. IR data $\left(\mathrm{cm}^{-1}\right): 3239$ (m), $2960(\mathrm{w})$, $2927(w), 2848(w), 2813(w), 1673(w), 1625(w), 1459(w)$, $1421(\mathrm{w}), 1375(\mathrm{w}), 1261(\mathrm{w}), 1213(\mathrm{w}), 1140(\mathrm{w}), 1099(\mathrm{~s})$, $1060(\mathrm{~s}), 972(\mathrm{~s}), 817(\mathrm{~m}), 781(\mathrm{~m}), 638(\mathrm{w}), 569(\mathrm{~m}), 484(\mathrm{~m})$.

2.3. The Preparation of $\left[\mathrm{Mg}_{1.5}\left(\mathrm{H}_{2} \mathrm{O}\right)_{9}\right] \cdot\left(\mathrm{L}^{-} \mathrm{H}_{2}\right)_{1.5} \cdot 6 \mathrm{H}_{2} \mathrm{O}$ 2. A mixture of $0.096 \mathrm{~g}(0.8 \mathrm{mmol}) \mathrm{MgSO}_{4}, 0.22 \mathrm{~g}(0.8 \mathrm{mmol})$ $\mathrm{H}_{4} \mathrm{~L}, \quad 0.01 \mathrm{~g} \quad(0.04 \mathrm{mmol}) \quad 4,4^{\prime}$-bipyridine, and $10.0 \mathrm{~mL}$ $(555 \mathrm{mmol})$ deionized water was sealed in a $23 \mathrm{~mL}$ Teflonlined stainless steel autoclave, and then heated at $160^{\circ} \mathrm{C}$ for $168 \mathrm{~h}$. The crystals of (2) (colorless block-shaped) were collected by vacuum filtration, washed thoroughly with deionized water, and dried in air (yield $75 \%$ based on magnesium atom). Elemental analysis, $\mathrm{C}_{6} \mathrm{H}_{34} \mathrm{~N}_{2} \mathrm{O}_{16} \mathrm{P}_{2} \mathrm{Mg}$ : C 15.11, H 7.13, N 5.87. Calcd.: C 15.04, H 7.06, N 5.79\%. IR data $\left(\mathrm{cm}^{-1}\right)$ : $3288(\mathrm{~m}), 3233(\mathrm{w}), 3010(\mathrm{~m}), 2981(\mathrm{w}), 2912$ (w), $1687(\mathrm{w}), 1584(\mathrm{w}), 1456(\mathrm{w}), 1436(\mathrm{w}), 1386(\mathrm{w}), 1265$ $(\mathrm{w}), 1211(\mathrm{w}), 1147(\mathrm{~s}), 1076(\mathrm{~s}), 1025(\mathrm{~s}), 921(\mathrm{~m}), 825(\mathrm{w})$, $761(\mathrm{~m}), 601(\mathrm{~m}), 553(\mathrm{~m}), 505(\mathrm{~m}), 434(\mathrm{w})$.

2.4. Crystallography. Single crystals of both 1 and 2 were mounted on a Siemens Smart CCD diffractometer equipped with graphite-monochromated Mo $\mathrm{K} \alpha$ radiation $(\lambda=$ $0.71073 \AA$ ) at $293 \mathrm{~K}$ using the $\omega-2 \theta$ scan technique. Their structures were solved by direct methods and refined by fullmatrix least-squares fitting on $F^{2}$ by SHELXL-97. All nonhydrogen atoms were refined with anisotropic thermal parameters. The positions of hydrogen atoms were either located by difference Fourier maps or calculated geometrically and their contributions in structural factor calculations were included. The crystallographic data and structural refinements are summarized in Table 1. Selected bond lengths $(\AA)$ and angles $\left({ }^{\circ}\right)$ of 1-2 are listed in Table S1 (see supplementary material available online at http://dx.doi.org/10.1155/2013/378379). The hydrogen bond lengths $(\AA)$ and angles $\left(^{\circ}\right)$ of 1-2 are given in Table S2 (see Supplementary material). CCDC nos. 852680 and 852681 contain the supplementary crystallographic data for this paper, respectively. The data can be obtained free of charge from The Cambridge Crystallographic Data Centre via http://www.ccdc.cam.ac.uk/data_request/cif.

\section{Results and Discussion}

3.1. Description of Structures. The asymmetric unit of $\mathbf{1}$ (Figure 1(a)) contains two crystallographically independent $\mathrm{Ba}(\mathrm{II})$ ions, one $\mathrm{L}^{4-}$ ligand, nine coordinated water molecules, and three lattice water molecules. $\mathrm{Ba}(1)$ ion is 8 coordinated with two phosphonate oxygen atoms $\left(\mu_{2}-\mathrm{O}(1)\right.$ and $\left.\mu_{2}-\mathrm{O}(4)\right)$ and six coordinated water molecules $\left(\mu_{2}-\mathrm{O}(7), \mathrm{O}(8), \mu_{2}-\mathrm{O}(9), \mathrm{O}(10), \mu_{2}-\mathrm{O}(11)\right.$, and $\left.\mathrm{O}(12)\right)$ to give rise to its two caps triangular prism coordination geometry. $\mathrm{Ba}(2)$ ion shows the layout of 9-coordination with three caps triangular prism geometry, surrounded by three phosphonate oxygen atoms $\left(\mu_{2}-\mathrm{O}(1), \mu_{2}-\mathrm{O}(4)\right.$, and $\left.\mathrm{O}(2)\right)$ and six water oxygen atoms $\left(\mu_{2}-\mathrm{O}(7), \mathrm{O}(13), \mathrm{O}(14), \mathrm{O}(15)\right.$, 


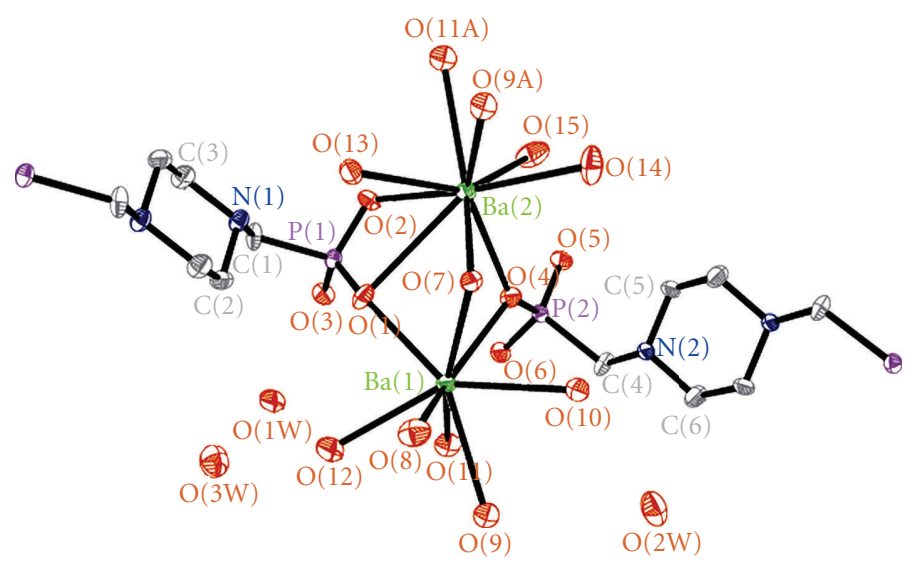

(a)
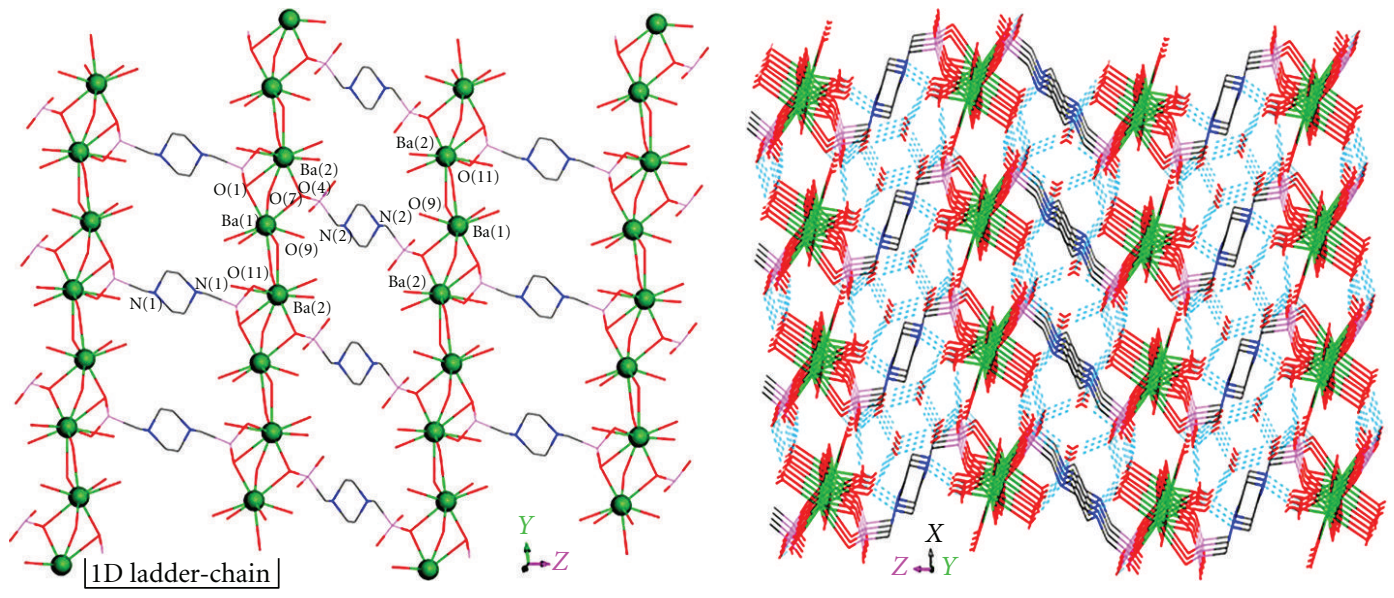

(b)

Figure 1: (a) Molecular structure of 1 showing the atom-labeling scheme (50\% thermal ellipsoids). (b) 2-D layer built from inorganic chains and organic linker in the $b c$ plane (left), and the 3-D supramolecular network of 1 stacked by hydrogen bonds along the $y$-axis (right) (Green: Ba, Pink: P, Grey: C, Red: O, Blue: N, White: H).

$\mu_{2}-\mathrm{O}(9 \mathrm{~A})$, and $\left.\mu_{2}-\mathrm{O}(11 \mathrm{~A})\right)$. Ba-O bond lengths are in the

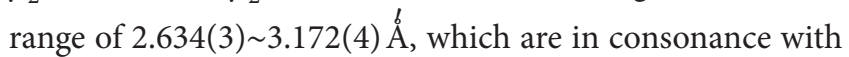
those of $\mathrm{Ba}(\mathrm{II})$ compounds $[17,18]$. There are two types of coordination patterns for the ligand $\mathrm{L}^{4-}$ in $\mathbf{1}$ (Scheme 1 ). One is the form of hexadentate ligand. Each phosphonate group of the ligand $\mathrm{L}^{4-}$, as both a bi- and monodentate ligand, uses two of three oxygen atoms to coordinate with two $\mathrm{Ba}(\mathrm{II})$ atoms in $\mu_{2}: \eta^{2} \eta^{1} \eta^{0}$ mode. This mode has only been found in the compound $\mathrm{Nd}_{2}\left(\mathrm{H}_{2} \mathrm{~L}\right)_{3} \cdot 9 \mathrm{H}_{2} \mathrm{O}$ reported by Groves et al. [6]. It is similar to those of the reported compounds $\mathrm{KCeL}_{4} \cdot 4 \mathrm{H}_{2} \mathrm{O}$ and $\mathrm{La}_{2} \mathrm{~L} \cdot \mathrm{H}_{2} \mathrm{~L} \cdot 4.5 \mathrm{H}_{2} \mathrm{O}$ [7]. Most of the reported cases act as monodentate donors to bridge with metal centers [8-11]. The other is only a bidentate ligand, in which one of three oxygen atoms is in service to bridge with two $\mathrm{Ba}(\mathrm{II})$ atoms in $\mu_{2}: \eta^{2} \eta^{0} \eta^{0}$ mode. The pure coordination mode has never been observed in all the $\mathrm{H}_{4} \mathrm{~L}$-compounds; however, the complicated coordination modes containing this manner have been reported for a phosphonate group [5]. The uncoordinated phosphonate oxygen atoms and nine coordinated water oxygen atoms are involved in the formation of hydrogen bonds. The highdimensional materials could be developed harmoniously with the multidirectional coordination strategy adopted. Regarding it as the secondary building unit (SBU), the combinatorial polyhedra $\left[\mathrm{Ba}(1) \mathrm{Ba}(2) \mathrm{O}_{14}\right]_{n}$, made of a two caps triangular prism $\left[\mathrm{Ba}(1) \mathrm{O}_{8}\right]$ and a three caps triangular prism $\left[\mathrm{Ba}(2) \mathrm{O}_{9}\right]$ via planar-shared three oxygen atoms $(\mathrm{O}(1), \mathrm{O}(4)$, and $\mathrm{O}(7)$ ), are connected with each other by edge-shared two oxygen atoms $(\mathrm{O}(9), \mathrm{O}(11))$ to result in a $1 \mathrm{D}$ inorganic single chain viewed along the $b$-axis. Under the action of piperazine moiety $(\mathrm{N}(1))$ of $\mathrm{H}_{4} \mathrm{~L}$, a $1 \mathrm{D}$ ladder-chain is born out from the single chain. Then the ladder-chains further expand to a $2 \mathrm{D}$ layer with inorganic-organic alternative arrangement through bridging piperazine moiety $(\mathrm{N}(2)$ ) in the $b c$ plane (Figure 1(b) left). Layer of this type is analogous to those in $3 \mathrm{D}$ metal- $\mathrm{H}_{4} \mathrm{~L}$ frameworks such as $\left[\mathrm{Sr}\left(\mathrm{H}_{2} \mathrm{~L}\right)\left(\mathrm{H}_{2} \mathrm{O}\right)_{2}\right] \cdot 3 \mathrm{H}_{2} \mathrm{O}[8]$ and $\left[\mathrm{M}\left(\mathrm{H}_{2} \mathrm{~L}\right)\right] \cdot \mathrm{H}_{2} \mathrm{O}\left(\mathrm{M}=\mathrm{Mn}^{\mathrm{II}}\right.$, $\mathrm{Co}^{\mathrm{II}}$ ) [14]. All the lattice water molecules are located in the inter-layers. There are many complicated hydrogen bonds in the structure, in which hydrogen bonds formed among the lattice water molecules. The hydrogen bonds play an 


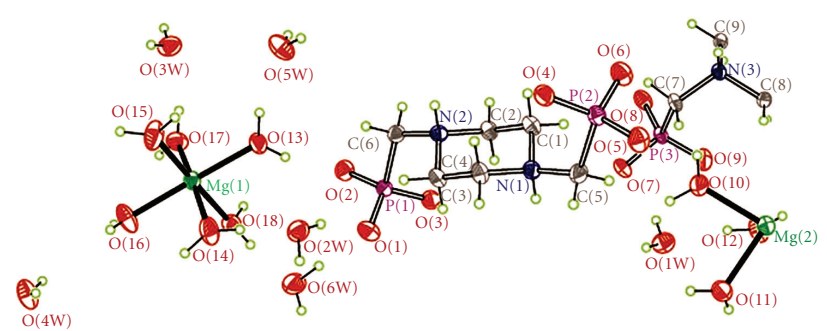

(a)
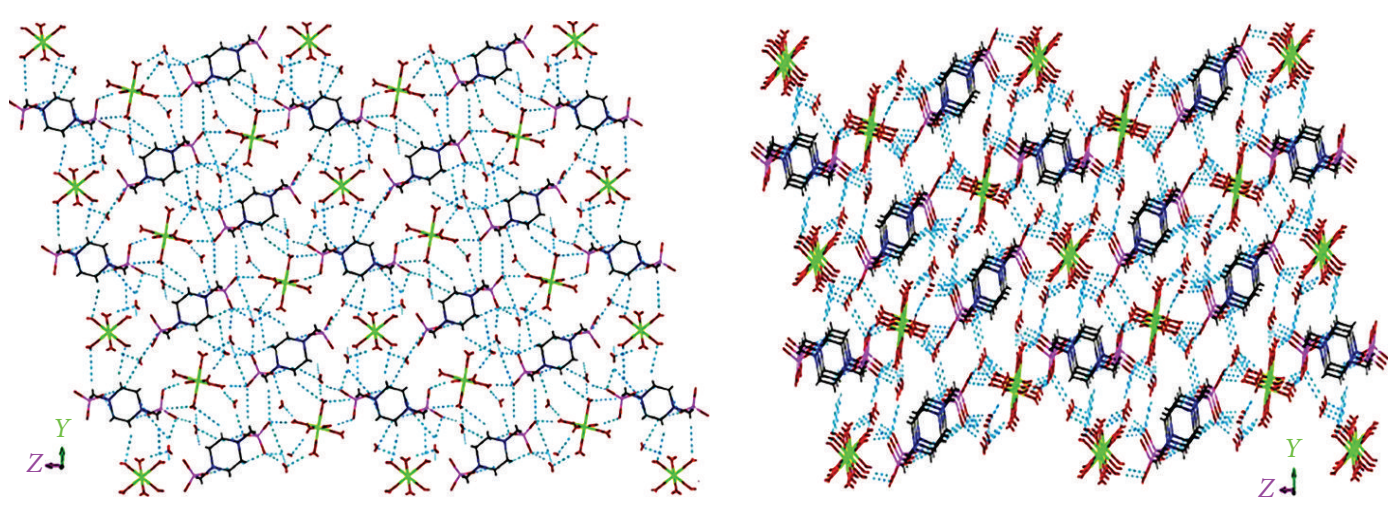

(b)

FIGURE 2: (a) ORTEP view of 2 showing the atom-labeling scheme (30\% thermal ellipsoids). (b) The 2-D layer in the $b c$ plane and the 3-D supramolecular network of 2 stacked by hydrogen bonds. (Green: Mg, Pink: P, Grey: C, Red: O, Blue: N, White: H).

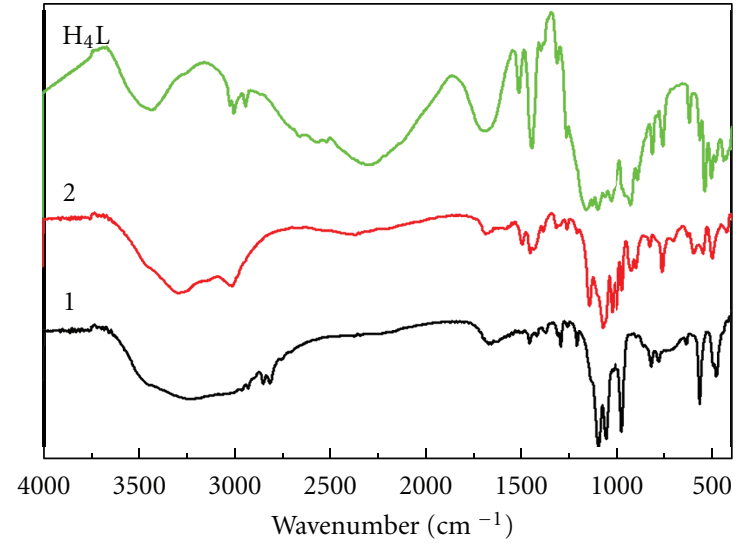

FIgURE 3: FT-IR spectra of 1-2 and the ligand $\mathrm{H}_{4} \mathrm{~L}$.

important role in the construction of the 3D supramolecular network (Figure 1(b) right). They are $\mathrm{O}(3 \mathrm{~W}) \cdots \mathrm{O}(1 \mathrm{~W})$

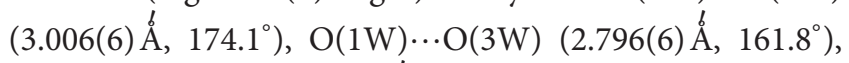
$\mathrm{O}(2 \mathrm{~W}) \cdots \mathrm{O}(5) \quad\left(2.802(5) \AA \AA^{\circ}, \quad 169.4^{\circ}\right), \quad \mathrm{O}(2 \mathrm{~W}) \cdots \mathrm{O}(15)$

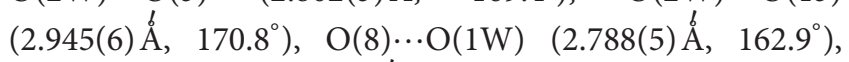
$\mathrm{O}(12) \cdots \mathrm{O}(3 \mathrm{~W})\left(2.792(6) \stackrel{b}{\mathrm{~A}}, 153.0^{\circ}\right)$ and $\mathrm{O}(14) \cdots \mathrm{O}(2 \mathrm{~W})$ (2.795(6) $\left.\mathrm{A}^{\circ}, 146.7^{\circ}\right)$, respectively. The weak intermolecular interactions not only take part in the construction of a 3-D supramolecular network but also stabilize the structure. Accordingly, existence of the molecular weak interactions might bring about the peculiar properties for compounds.
Single-crystal X-ray diffraction analysis reveals that compound 2 possesses a zero-dimensional mononuclear structure, in which the asymmetric unit (Figure 2(a)) contains one and a half crystallographically independent metal cations $\mathrm{Mg}(\mathrm{II})$, one and a half ligand anions $\left(\mathrm{L}-\mathrm{H}_{2}\right)^{2-}$, and nine aqua ligands along with six lattice water molecules. $\mathrm{Mg}(1)$ centre adopts octahedral configuration $\left[\mathrm{MgO}_{6}\right]^{2+}$ to coordinate with six oxygen atoms from six lattice water molecules, so is $\mathrm{Mg}(2)$ centre. $\mathrm{Mg}(\mathrm{II})-\mathrm{O}$ bond lengths fall in a narrow range of 2.0321(2) 2.0996(2) $\AA$, basically close to those of $\mathrm{Mg}(\mathrm{II})$ compounds [18]. The cis- and trans-angles of $\mathrm{O}-\mathrm{Mg}(\mathrm{II})-\mathrm{O}$ are $84.92(7)^{\circ} \sim 95.80(9)^{\circ}$ and $170.86(9)^{\circ} \sim 178.33(8)^{\circ}$, respectively, which slightly deviate from those of the ideal octahedron. The ligand $\left(\mathrm{L}-\mathrm{H}_{2}\right)^{2-}$ is a trend for loneliness as a result of $\mathrm{Mg}$ (II) ions surrounded by water molecules. In consideration of extremely strong hydration of the $\mathrm{Mg}^{2+}$ ion, anhydrous $\mathrm{MgSO}_{4}$ is used during the synthesis. Although different kinds of solvent have been used in the synthesis process, the compound $\mathbf{2}$ can only be obtained in aqueous solution under the same conditions. A systemic research on looking for solvents that benefit the crystal growth will continue to do so in future. For the sake of charge balance, both nitrogen atoms $(\mathrm{N}(1), \mathrm{N}(2))$ of the ligand $\mathrm{L}^{4-}$ are protonated in 2 . All the phosphonate oxygen atoms are deprotonated and participate in the formation of hydrogen bonds. Both the octahedral cation $\left[\mathrm{MgO}_{6}\right]^{2+}$ and the ligand anion $\left(\mathrm{L}-\mathrm{H}_{2}\right)^{2-}$ are alternately arranged and are connected with each other by hydrogen bonds, $\mathrm{O}(13) \cdots \mathrm{O}(2)$ $\left(2.749(2) \AA \hat{L}, 166.4^{\circ}\right), \mathrm{O}(13) \cdots \mathrm{O}(5 \mathrm{~W})\left(2.772(3) \AA \hat{A}, 163.3^{\circ}\right)$, 


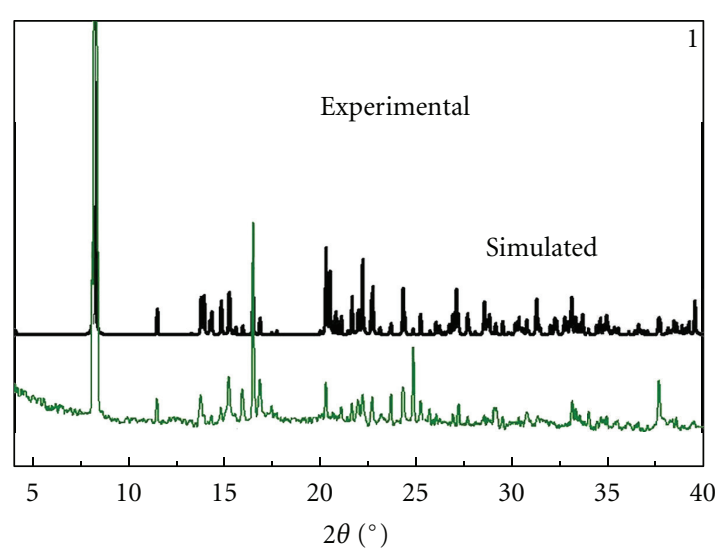

(a)

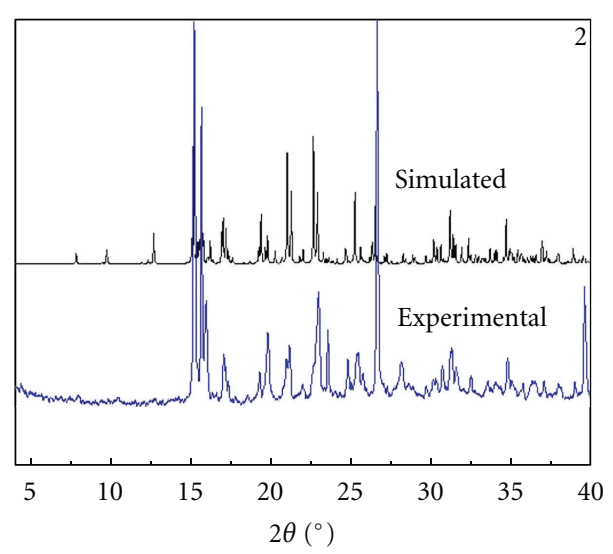

(b)

FIGURE 4: Experimental and simulated powder X-ray diffraction patterns of $\mathbf{1}$ (a) and 2 (b).

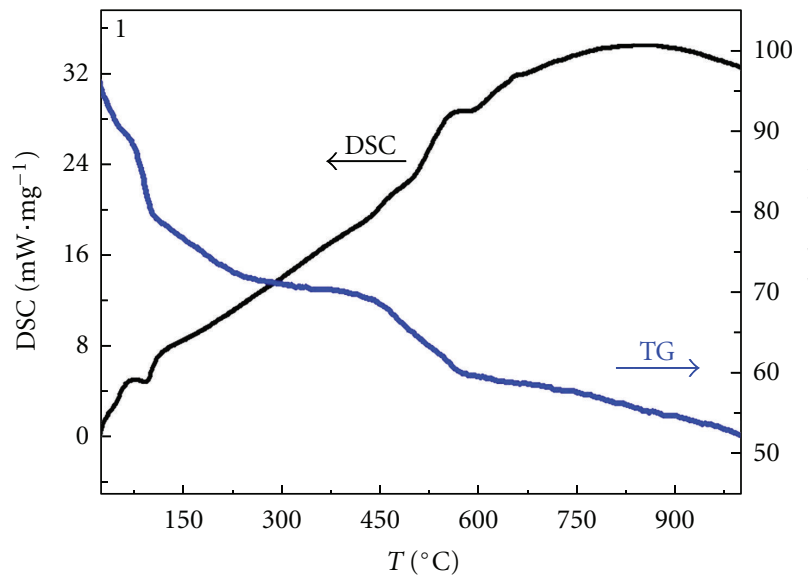

(a)

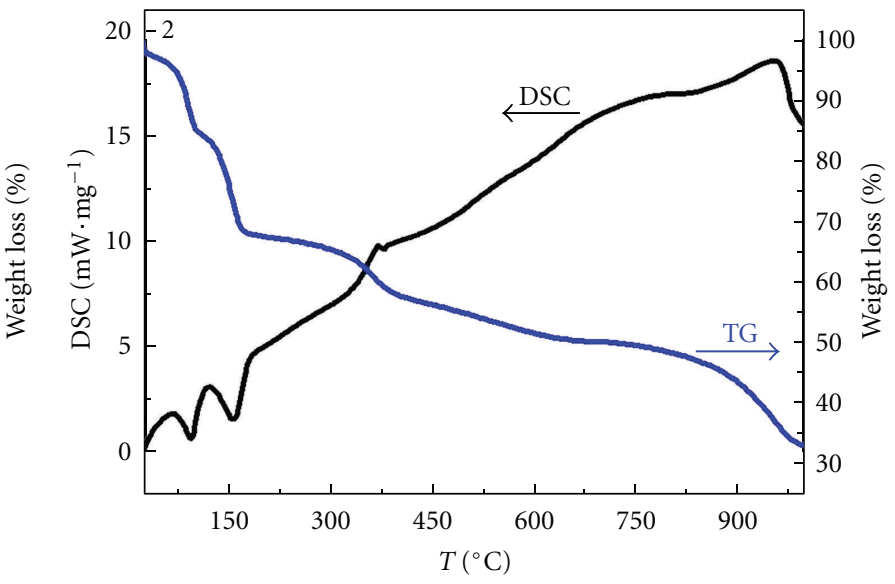

(b)

Figure 5: The TGA-DSC curves of $\mathbf{1}$ (a) and $\mathbf{2}$ (b).
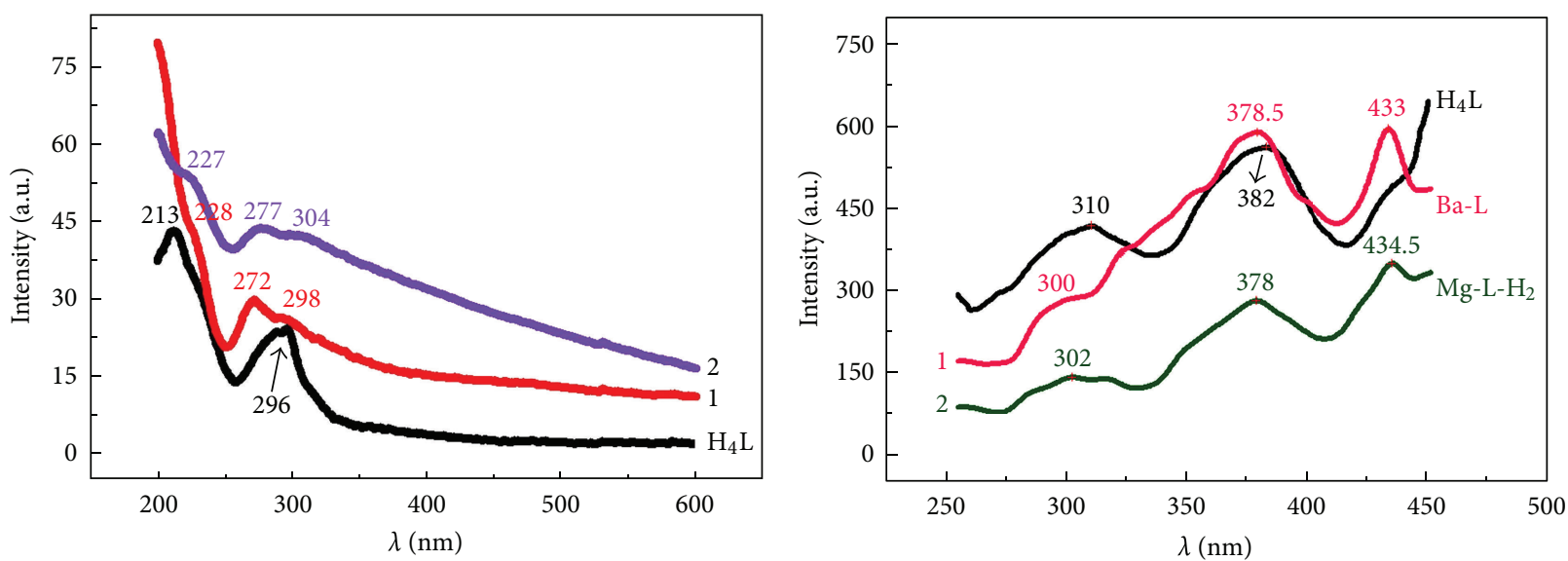

(1) Ba-L

(2) $\mathrm{Mg}-\mathrm{L}-\mathrm{H}_{2}$

(a)

(b)

Figure 6: The solid state UV-Vis spectra (a) and fluorescent spectra (b) of the two compounds and the ligand $\mathrm{H}_{4} \mathrm{~L}$ under the excitation of $235 \mathrm{~nm}$. Note: the fluorescent intensity decay for $\mathrm{H}_{4} \mathrm{~L}$ is $1 \% \mathrm{~T}$ attenuation and those of the other two are normal. 
TABle 1: Crystallographic data for 1-2.

\begin{tabular}{|c|c|c|}
\hline & 1 & 2 \\
\hline Empirical formula & $\mathrm{C}_{6} \mathrm{H}_{36} \mathrm{Ba}_{2} \mathrm{~N}_{2} \mathrm{O}_{18} \mathrm{P}_{2}$ & $\mathrm{C}_{9} \mathrm{H}_{51} \mathrm{~N}_{3} \mathrm{O}_{24} \mathrm{P}_{3} \mathrm{Mg}_{1.5}$ \\
\hline Formula weight & 760.97 & 714.9 \\
\hline Temperature (K) & $296(2) \mathrm{K}$ & 296(2) K \\
\hline Wavelength $(\AA)$ & $0.71073 \AA$ & $0.71073 \AA$ \\
\hline Crystal system & Triclinic & Triclinic \\
\hline Space group & $P \overline{1}$ & $P_{\overline{1}}$ \\
\hline \multicolumn{3}{|l|}{ Unit cell dimensions } \\
\hline$a(\AA)$ & $6.9479(8)$ & $5.7894(1)$ \\
\hline$b(\AA)$ & $8.6291(1)$ & $11.803(3)$ \\
\hline$c(\AA)$ & $21.850(2)$ & $22.685(5)$ \\
\hline$\alpha\left(^{\circ}\right)$ & $82.7950(1)$ & $76.850(2)$ \\
\hline$\beta\left(^{\circ}\right)$ & $81.3570(1)$ & $89.656(2)$ \\
\hline$\gamma\left({ }^{\circ}\right)$ & $68.7620(1)$ & $81.516(2)$ \\
\hline Volume $\left(\AA^{3}\right)$ & $1203.6(2)$ & $1492.3(6)$ \\
\hline$Z$ & 2 & 3 \\
\hline Calculated density $\left(\mathrm{g} / \mathrm{cm}^{3}\right)$ & 2.100 & 1.591 \\
\hline Absorption coefficient $\left(\mathrm{mm}^{-1}\right)$ & 3.462 & 0.329 \\
\hline$F(000)$ & 744 & 762 \\
\hline \multirow[t]{2}{*}{ Theta range for data collection $\left({ }^{\circ}\right)$} & $0.95^{\circ}-24.99^{\circ}$ & $0.92^{\circ}-25.00^{\circ}$ \\
\hline & $-8 \leq h \leq 8$ & $-6 \leq h \leq 6$ \\
\hline \multirow[t]{2}{*}{ Limiting indices } & $-9 \leq k \leq 10$ & $-14 \leq k \leq 13$ \\
\hline & $-25 \leq l \leq 25$ & $-26 \leq l \leq 26$ \\
\hline Unique ( $R($ int $))$ & $8512 / 4182(R($ int $)=0.0258)$ & $10567 / 5248(R($ int $)=0.0226)$ \\
\hline Maximum and minimum transmission & 0.354 and 0.260 & 0.952 and 0.924 \\
\hline Data/restraints/parameters & $4182 / 0 / 271$ & $5248 / 0 / 367$ \\
\hline Goodness-of-fit on $F^{2}$ & 1.137 & 1.059 \\
\hline Final $R$ indices $(I>2 \sigma(I))$ & $R_{1}=0.0267, w R_{2}=0.0725$ & $R_{1}=0.0379, w R_{2}=0.1106$ \\
\hline$R$ indices (all data) & $R_{1}=0.0310, w R_{2}=0.0854$ & $R_{1}=0.0438, w R_{2}=0.1149$ \\
\hline Largest different peak and hole $\left(\mathrm{e} \cdot \AA^{-3}\right)$ & 0.598 and $-0.659 \mathrm{e} \cdot \AA^{-3}$ & 0.445 and $-0.358 \mathrm{e} \cdot \AA^{-3}$ \\
\hline
\end{tabular}

$\mathrm{O}(17) \cdots \mathrm{O}(3 \mathrm{~W}) \quad\left(2.694(3) \stackrel{\mathrm{A}}{ }, \quad 167.7^{\circ}\right), \quad \mathrm{O}(2 \mathrm{~W}) \cdots \mathrm{O}(1)$ $\left(2.693(2) \AA\right.$ A, $\left.162.0^{\circ}\right), \quad \mathrm{O}(3 \mathrm{~W}) \cdots \mathrm{O}(7)(2.765(2) \AA$ $\mathrm{O}(6 \mathrm{~W}) \cdots \mathrm{O}(1) \quad\left(2.776(3) \AA \mathrm{A}^{\circ}, 177.8^{\circ}\right)$, and $\mathrm{O} 5 \mathrm{~W} \cdots \mathrm{O}(3)$ $\left(2.724(2) \AA\right.$ A, $\left.166.7^{\circ}\right)$, to build a 1-D fishbone chain along the $c$-axis. The above hydrogen bonds are formed among the phosphonate oxygen atoms $(\mathrm{O}(1), \mathrm{O}(2), \mathrm{O}(3), \mathrm{O}(7)$, $\mathrm{O}(8))$ and the water oxygen atoms $(\mathrm{O}(13), \mathrm{O}(15), \mathrm{O}(17)$, $\mathrm{O}(2 \mathrm{~W}), \mathrm{O}(3 \mathrm{~W}), \mathrm{O}(5 \mathrm{~W}), \mathrm{O}(6 \mathrm{~W}))$. A great number of the adjacent 1-D fishbone chains further spread out through the hydrogen bond interactions in the $b c$ plane to give rise to a 2 D supramolecular layer (Figure 2(b) left), in which the lattice water molecules are situated at interlayers. The complicated hydrogen bonds carry 2-D supramolecular layer forward into a 3-D supramolecular network unceasingly (Figure 2(b) right). The hydrogen bonds should be contributed enormously to the construction of the supramolecular structure and some of the most important potential application performance.
3.2. FTIR Spectroscopy. The IR spectra for the title compounds and the ligand $\mathrm{H}_{4} \mathrm{~L}$ were recorded in the region from 4000 to $400 \mathrm{~cm}^{-1}$ (Figure 3). The broad bands at $3239 \mathrm{~cm}^{-1}$ for 1 and $3288 \mathrm{~cm}^{-1}, 3233 \mathrm{~cm}^{-1}$ for 2 are due to the $\mathrm{H}-\mathrm{OH}$ stretching vibration of the water molecule, while the band at $3428 \mathrm{~cm}^{-1}$ for the ligand $\mathrm{H}_{4} \mathrm{~L}$ is attributed to $\mathrm{P}-\mathrm{OH}$ stretching vibration. The weak band in 2 appeared at $3010 \mathrm{~cm}^{-1}$ can be due to $\mathrm{N}-\mathrm{H}$ group stretching; however, in $\mathbf{1}$ and $\mathrm{H}_{4} \mathrm{~L}$ it is absent as these contain no protonated nitrogen atoms. The bands, at $2960 \mathrm{~cm}^{-1}, 2927 \mathrm{~cm}^{-1}, 2848 \mathrm{~cm}^{-1}$, and $2813 \mathrm{~cm}^{-1}$ for $1,2981 \mathrm{~cm}^{-1}, 2912 \mathrm{~cm}^{-1}$ for 2 , and $3002 \mathrm{~cm}^{-1}, 2941 \mathrm{~cm}^{-1}$ for $\mathrm{H}_{4} \mathrm{~L}$, can be attributed to the asymmetric and symmetric $\mathrm{C}-\mathrm{H}$ stretching vibrations of the $-\mathrm{CH}_{2}$ - groups, respectively. The bands in the region of $2700 \sim 2200 \mathrm{~cm}^{-1}$ are $v(\mathrm{PO}-\mathrm{H})$ for $\mathrm{H}_{4} \mathrm{~L}$, which are characteristic of hydrogen phosphonate groups. However, there are no peaks in this region for 1-2, which means the change of configuration of $\mathrm{H}_{4} \mathrm{~L}$ in 1-2. The peaks at $1673 \mathrm{~cm}^{-1}$ for $1,1687 \mathrm{~cm}^{-1}$ for 2 , and $1689 \mathrm{~cm}^{-1}$ 
for $\mathrm{H}_{4} \mathrm{~L}$ may be due to an overtone or combination band of the $\mathrm{C}-\mathrm{PO}_{3}$ stretching vibrations, slightly blue-shifting than that of $\mathrm{H}_{4} \mathrm{~L}$. The weak bands at $1625 \mathrm{~cm}^{-1}$ for $\mathbf{1}$ and $1584 \mathrm{~cm}^{-1}$ for 2 are due to the $\delta(\mathrm{H}-\mathrm{OH})$ vibration, but there is missing data in this region for $\mathrm{H}_{4} \mathrm{~L}$. The corresponding $\delta\left(-\mathrm{CH}_{2}-\right)$ deformation bands appear at $1459 \mathrm{~cm}^{-1}$, $1421 \mathrm{~cm}^{-1}$, and $1375 \mathrm{~cm}^{-1}$ for $1,1456 \mathrm{~cm}^{-1}, 1436 \mathrm{~cm}^{-1}$, and $1386 \mathrm{~cm}^{-1}$ for 2 , and $1448 \mathrm{~cm}^{-1}, 1440 \mathrm{~cm}^{-1}$, and $1382 \mathrm{~cm}^{-1}$ for $\mathrm{H}_{4} \mathrm{~L}$. The weak bands at $1261 \mathrm{~cm}^{-1}$ for $1,1265 \mathrm{~cm}^{-1}$ for 2 and $1267 \mathrm{~cm}^{-1}$ for $\mathrm{H}_{4} \mathrm{~L}$ can be assigned to the $\omega\left(-\mathrm{CH}_{2}-\right)$ vibration. The $\mathrm{P}=\mathrm{O}$ stretching vibrations are observed at $1213 \mathrm{~cm}^{-1}, 1140 \mathrm{~cm}^{-1}$ for $1,1211 \mathrm{~cm}^{-1}, 1147 \mathrm{~cm}^{-1}$ for 2 and $1213 \mathrm{~cm}^{-1}, 1160 \mathrm{~cm}^{-1}$ for $\mathrm{H}_{4} \mathrm{~L}$. The classic strong $-\mathrm{PO}_{3}$ vibrations (typically $1200-900 \mathrm{~cm}^{-1}$ ) [21] are at 1099 (vs), 1060 (vs), and $972 \mathrm{~cm}^{-1}$ (vs) for 1, 1076 (vs), 1025 (s), and $921 \mathrm{~cm}^{-1}$ (ms) for 2 , and $1103(\mathrm{~s}), 1031(\mathrm{~s})$ and $923 \mathrm{~cm}^{-1}$ (s) for $\mathrm{H}_{4} \mathrm{~L}$. All of these peaks can be assigned to the stretching vibrations associated with the $\mathrm{N}-\mathrm{C}$ bonds and the $\mathrm{CPO}_{3}$ tetrahedra. Compared with $\mathrm{H}_{4} \mathrm{~L}$, the changes of the IR spectra in the $v(\mathrm{PO})$ region show the coordination of oxygen atoms in phosphonic group with barium atoms in $\mathbf{1}$. The broad band at $923 \mathrm{~cm}^{-1} v(\mathrm{P}-\mathrm{OH})$ disappeared, but a new sharp band were observed at $971 \mathrm{~cm}^{-1}$ that can be attributed to $v\left(\mathrm{P}-\mathrm{O}^{-}\right)$ for 1 . In addition, the intensity differences and shifts of peaks from infrared spectra can bring us to the conclusion that the surrounding environment of the $\mathrm{H}_{4} \mathrm{~L}$ unit has been modified when coordinating with metal ions. Additional middle strong bands at low energy are found at $569 \mathrm{~cm}^{-1}$ and $484 \mathrm{~cm}^{-1}$ for $1,553 \mathrm{~cm}^{-1}$ and $505 \mathrm{~cm}^{-1}$ for 2 , and $572 \mathrm{~cm}^{-1}$ and $509 \mathrm{~cm}^{-1}$ for $\mathrm{H}_{4} \mathrm{~L}$. These bands are probably due to bending vibrations of the tetrahedral $\mathrm{O}_{3} \mathrm{PC}$ groups and $\mathrm{Ba}-\mathrm{O}$ (for $\mathbf{1}$ ) stretching vibrations.

3.3. PXRD and Thermal Characteristics. The powder XRD patterns of 1-2 indicate that as-synthesized products are the new materials, and the patterns are entirely consistent with the simulated those from the single-crystal X-ray diffractions (Figure 4).

TG-DSC measures were conducted to examine the stabilities of two compounds (Figure 5). The combined TGDSC analysis of $\mathbf{1}$ shows three major weight losses in $\mathrm{N}_{2}$ atmosphere. The first and the second mass losses of $28.35 \%$ from $50^{\circ} \mathrm{C}$ to $260^{\circ} \mathrm{C}$, with an endothermic peak centered at $94^{\circ} \mathrm{C}$, correspond to the losses of three lattice water molecules and nine aqua ligands (calc. 28.38\%). The third step of about $12.63 \%$ (calc. $12.69 \%$ ), in the range of $400-640^{\circ} \mathrm{C}$, can be assigned to the pyrolysis of the organic moieties of the ligand $\mathrm{H}_{4} \mathrm{~L}$. Two exothermic peaks centered at $463^{\circ} \mathrm{C}$ and $555^{\circ} \mathrm{C}$ indicate structural changes. From $640^{\circ} \mathrm{C}$, thermal decomposition is still continuing, and the final residue is mainly $\mathrm{Ba}_{2} \mathrm{P}_{2} \mathrm{O}_{6}$ at $1000^{\circ} \mathrm{C}$. The TGA curve of 2 consists of four weight losses in $\mathrm{N}_{2}$ atmosphere. The first loss of $15.19 \%$ with an endothermic peak centered at $94^{\circ} \mathrm{C}$ starts from $55^{\circ} \mathrm{C}$ and completes at about $110^{\circ} \mathrm{C}$, owing to the release of four lattice water molecules (calc. 15.11\%). The second weight loss of $22.56 \%$, from $110^{\circ} \mathrm{C}$ to $350^{\circ} \mathrm{C}$, can be attributed to nine coordinated water molecules (calc. 22.66\%). The third step from $350^{\circ} \mathrm{C}$ is the process of the decomposition of organic group until $820^{\circ} \mathrm{C}$, corresponding two exothermic peaks centered at $367^{\circ} \mathrm{C}$ and $732^{\circ} \mathrm{C}$. The last step with a small exothermic peak centered at $950^{\circ} \mathrm{C}$ covers a temperature range of $820^{\circ} \mathrm{C}-1000^{\circ} \mathrm{C}$, which corresponds to the continuios pyrolysis of the organic group of the ligand $\mathrm{H}_{4} \mathrm{~L}$. The final product is $\mathrm{MgP}_{2} \mathrm{O}_{6}$ and $\mathrm{MgO}(1: 1.3)$. The total weight losses of $67.27 \%$ agree with the calculated value $(67.13 \%)$.

3.4. Photophysical Properties. The solid-state UV-Vis spectra of both 1-2 and $\mathrm{H}_{4} \mathrm{~L}$ are shown in Figure 6(a). The three absorption bands observed at $213 \mathrm{~nm}, 229, \mathrm{~nm}$ and $296 \mathrm{~nm}$ for the free ligand $\mathrm{H}_{4} \mathrm{~L}, 228 \mathrm{~nm}, 272 \mathrm{~nm}$, and $298 \mathrm{~nm}$ for $\mathbf{1}$ and $227 \mathrm{~nm}, 277 \mathrm{~nm}$, and $304 \mathrm{~nm}$ for 2 , respectively. These bands may be the electron-releasing character of the $N$-substituent attached to the $-\mathrm{PO}_{3}$ group and caused by the $n \rightarrow \pi^{*}$ transition from the nitrogen atom to the $\mathrm{P}=\mathrm{O}$ group. The absorption bands of 1-2 can manifest a little red shift in the UV spectra, compared with those of the free ligand $\mathrm{H}_{4} \mathrm{~L}$. This may be that the total energy of system decreases after the coordination with $\mathrm{Ba}$ (II) ions for $\mathbf{1}$ and after the formation of a salt with $\mathrm{Mg}(\mathrm{II})$ ions for $\mathbf{2}$ along with hydrogen bonds.

Photoluminescent properties of alkaline earth metal complexes are not well studied as compared with those of transition metal and rare earth complexes [22]. The solid-state fluorescent properties of both 1-2 and $\mathrm{H}_{4} \mathrm{~L}$ were investigated at room temperature (Figure 6(b)). The free ligand $\mathrm{H}_{4} \mathrm{~L}$ emits two strong fluorescent bands (1\% T attenuation) centered at 310 and $382 \mathrm{~nm}$ under the excitation of $235 \mathrm{~nm}$, which derived from the photo-induced electron transfer (PET). The compound 1 with $\mathrm{Ba}(\mathrm{II})$ ion displays two main fluorescent bands centred at 378.5 and $433 \mathrm{~nm}$ with a shoulder peak at $300 \mathrm{~nm}$, and the compound 2 with $\mathrm{Mg}(\mathrm{II})$ ion also exhibits two strong fluorescent bands centred at 378 and $434.5 \mathrm{~nm}$ with a weak peak at $302 \mathrm{~nm}$ under the excitation of $235 \mathrm{~nm}$. These fluorescent bands could come from the intraligand $\pi^{*} \rightarrow n$ transition state of $\mathrm{H}_{4} \mathrm{~L}$. The emission intensity of $\mathrm{H}_{4} \mathrm{~L}$ is $1 \% \mathrm{~T}$ attenuation in the test and those of the other two are normal. Compared with those of the free ligand $\mathrm{H}_{4} \mathrm{~L}$, the high energy emission bands $(<400 \mathrm{~nm})$ of $\mathbf{1 - 2}$ are blueshifted slightly and show significant decreases in intensity. Moreover, the fluorescent intensity of $\mathbf{2}$ is less than that of 1. They are probably related to $\mathrm{O}-\mathrm{H} \cdots \mathrm{N}$ hydrogen bond interactions, the protonation of nitrogen atoms of $\mathrm{H}_{4} \mathrm{~L}$ as well as specific coordination environment around metal ions. The low energy emission bands (>400 nm) of 1-2 are most likely because of the coordination effect with metal (II) ions $[23,24]$. Investigation and consideration of $N$-heterocyclic systems in future may yield effective path for the preparation of luminescent materials.

\section{Conclusions}

We have firstly reported the preparation of two novel alkaline-earth phosphonate $\mathrm{CPs}, \quad\left[\mathrm{Ba}_{2}(\mathrm{~L})\left(\mathrm{H}_{2} \mathrm{O}\right)_{9}\right] \cdot 3 \mathrm{H}_{2} \mathrm{O}$ (1) and $\left[\mathrm{Mg}_{1.5}\left(\mathrm{H}_{2} \mathrm{O}\right)_{9}\right] \cdot\left(\mathrm{L}-\mathrm{H}_{2}\right)_{1.5} \cdot 6 \mathrm{H}_{2} \mathrm{O}$ (2), by using a hydrothermal technique. Hydrogen bonds and static electric forces have typically led to the 3-D supramolecular networks. 
Results of photoluminescence measurement indicate that the two compounds display three emission peaks, derived from the organic ligand and coordination effect. There are slight blueshift and the significant reduction in intensity in the high energy region for 1-2 as compared with the free ligand $\mathrm{H}_{4} \mathrm{~L}$. The behavior may be attributed to specific coordination environment around metal ions and lots of hydrogen bond interactions involving nitrogen atoms in the structure. So the work on the application of optical functional materials including alkaline-earth metals and $d^{10}$-metals is now in progress.

\section{Acknowledgments}

The authors are grateful to Open Fund of Jiangsu Key Laboratory for Chemistry of Low-Dimensional Materials, Cultivation Fund of High Level Project of Huaiyin Normal University, and the Natural Science Foundation of the Higher Education Institutions of Jiangsu Province, China (Projects nos. JSKC11092, 11HSGJBZ12, and 12KJA15004).

\section{References}

[1] J. Diwu and T. E. Albrecht-Schmitt, "Chiral uranium phosphonates constructed from achiral units with threedimensional frameworks," Chemical Communications, vol. 48, pp. 3827-3829, 2012.

[2] P. O. Adelani, A. G. Oliver, and T. E. Albrecht-Schmitt, "Hydrothermal synthesis and structural characterization of organically templated uranyl diphosphonate compounds," Crystal Growth and Design, vol. 11, no. 5, pp. 1966-1973, 2011.

[3] E. Matczak-Jon and V. Videnova-Adrabińska, "Supramolecular chemistry and complexation abilities of diphosphonic acids," Coordination Chemistry Reviews, vol. 249, no. 21-22, pp. 2458-2488, 2005.

[4] H. P. Perry, K. J. Gagnon, J. Law, S. Teat, and A. Clearfield, "Divalent metal phosphonate coordination polymers constructed from a dipiperidine-based bisphosphonate ligand," Dalton Transactions, vol. 41, pp. 3985-3894, 2012.

[5] S. R. Miller, G. M. Pearce, P. A. Wright et al., "Structural transformations and adsorption of fuel-related gases of a structurally responsive nickel phosphonate metal-organic framework, NiSTA-12," Journal of the American Chemical Society, vol. 130, no. 47, pp. 15967-15981, 2008.

[6] J. A. Groves, N. F. Stephens, P. A. Wright, and P. Lightfoot, "Novel open-framework architectures in lanthanide phosphonates," Solid State Sciences, vol. 8, no. 3-4, pp. 397-403, 2006.

[7] J. P. S. Mowat, J. A. Groves, M. T. Wharmby et al., "Lanthanide $N, N^{\prime}$-piperazine-bis(methylenephosphonates) ( $\mathrm{Ln}=\mathrm{La}, \mathrm{Ce}$, $\mathrm{Nd}$ ) that display flexible frameworks, reversible hydration and cation exchange," Journal of Solid State Chemistry, vol. 182, no. 10, pp. 2769-2778, 2009.

[8] Z.-Y. Du, Y.-R. Xie, and H.-R. Wen, "Novel open-framework architecture in strontium(II) phosphonate," Inorganica Chimica Acta, vol. 362, p. 351, 2009.

[9] M. Taddei, F. Costantino, and R. Vivani, "Synthesis and crystal structure from X-ray powder diffraction data of Two zirconium diphosphonates containing piperazine groups," Inorganic Chemistry, vol. 49, no. 20, pp. 9664-9670, 2010.
[10] Y. Wang, S. S. Bao, W. Xu, J. S. Chen, S. Gao, and L. M. Zheng, "Structure and magnetic properties of a novel copper diphosphonate with pillared layered structure:: $\mathrm{Cu}_{2}\left(\mathrm{H}_{2} \mathrm{O}\right)_{2} \mathrm{O}_{3} \mathrm{PCH}_{2} \mathrm{~N}\left(\mathrm{C}_{2} \mathrm{H}_{4}\right)_{2} \mathrm{NCH}_{2} \mathrm{PO}_{3}$," Journal of Solid State Chemistry, vol. 177, pp. 1297-1301, 2004.

[11] J. A. Groves, P. A. Wright, and P. Lightfoot, "Two closely related lanthanum phosphonate frameworks formed by anion-directed linking of inorganic chains," Inorganic Chemistry, vol. 44, no. 6, pp. 1736-1739, 2005.

[12] Z. Y. Du, H. B. Xu, and J. G. Mao, "Rational design of 0D, 1D, and 3D open frameworks based on tetranuclear lanthanide(III) sulfonate-phosphonate clusters," Inorganic Chemistry, vol. 45, pp. 9780-9788, 2006.

[13] K. R. Ma, D. J. Zhang, and Y. L. Zhu, "Structure and characterization of a novel 3D lead phosphonate metal-organic framework with cationic layer based on weak $\mathrm{Pb}-\mathrm{O}(\mathrm{N})$ contact," Australian Journal of Chemistry, vol. 63, pp. 452-457, 2010.

[14] R. LaDuca, D. Rose, J. R. D. DeBord, R. C. Haushalter, C. J. O'Connor, and J. Zubieta, “Three-dimensional metal piperazinyldiphosphonate phases with ellipsoidal cavities defined by 44-membered rings: crystal structures of $\left[\mathrm{MO}_{3} \mathrm{PCH}_{2} \mathrm{NH}\left(\mathrm{C}_{2} \mathrm{H}_{4}\right)_{2} \mathrm{NHCH}_{2} \mathrm{PO}_{3}\right] \cdot \mathrm{H}_{2} \mathrm{O}, \mathrm{M}=\mathrm{Mn}$ and $\mathrm{Co}$," Journal of Solid State Chemistry, vol. 123, no. 2, pp. 408-412, 1996.

[15] A. E. Platero-Prats, V. A. de la Pen a-O'Shea, D. M. Proserpio, N. Snejko, E. Gutiérrez-Puebla, and A. Monge, "Insight into the SBU condensation in $\mathrm{mg}$ coordination and supramolecular frameworks: a combined experimental and theoretical study," Journal of the American Chemical Society, vol. 134, pp. 4762-4771, 2012.

[16] D. Banerjee and J. B. Parise, "Recent advances in s-block metal carboxylate networks," Crystal Growth \& Design, vol. 11, pp. 4704-4720, 2011.

[17] K. R. Ma, Y. L. Zhu, Q. F. Yin, H. Y. Hu, and F. Ma, "Structure and characterization of a novel 3-D Ba(II)-MOF based on (Ba4O7) core," Journal of Chemical Research, vol. 34, p. 705, 2010.

[18] K. D. Demadis, S. D. Katarachia, R. G. Raptis, H. Zhao, and P. Baran, "Alkaline earth metal organotriphosphonates: inorganicorganic polymeric hybrids from dication-dianion association," Crystal Growth and Design, vol. 6, no. 4, pp. 836-838, 2006.

[19] E. Montoneri, "High temperature sulphonation of benzene phosphonic acid in liquid sulphur trioxide," Phosphorus, Sulfur, and Silicon and the Related Elements, vol. 55, pp. 201-204, 1991.

[20] E. Montoneri, M. C. Gallazzi, and M. Grassi, "Organosulphur phosphorus acid compounds-part 1. m-Sulphophenylphosphonic acid," Journal of the Chemical Society, Dalton Transactions, no. 9, pp. 1819-1823, 1989.

[21] S. Bauer, T. Bein, and N. Stock, "Inorganic-organic hybrid compounds: synthesis and characterization of three new metal phosphonates with similar characteristic structural features," Journal of Solid State Chemistry, vol. 179, pp. 145-155, 2006.

[22] H. F. Zhu, Z. H. Zhang, W. Y. Sun, T. A. Okamura, and N. Ueyama, "Syntheses, structures, and properties of twodimensional alkaline earth metal complexes with flexible tripodal tricarboxylate ligands," Crystal Growth and Design, vol. 5, no. 1, pp. 177-182, 2005.

[23] J.-C. Zhou, B.-Y. Zhou, X.-J. Ma, T. T. Cheng, N.-X. Li, and H.$\mathrm{J} . \mathrm{Xu}$, "Synthesis, structure and properties of the first organictemplated inorganic-framework $\mathrm{Ba}(\mathrm{II})$ perchlorate," Journal of Molecular Structure, vol. 1006, p. 441, 2011. 
[24] S.-Q. Zang, Y. Su, J.-G. Lin, Y.-Z. Li, S. Gao, and Q.-J. Meng, "Four coordination polymers constructed from a multicarboxylate ligand and metal centers various from $\mathrm{Ba} 2+, \mathrm{Cu} 2+, \mathrm{Zn} 2+$ to Gd3+: Syntheses, crystal structures and properties," Inorganica Chimica Acta, vol. 362, p. 2440, 2009. 

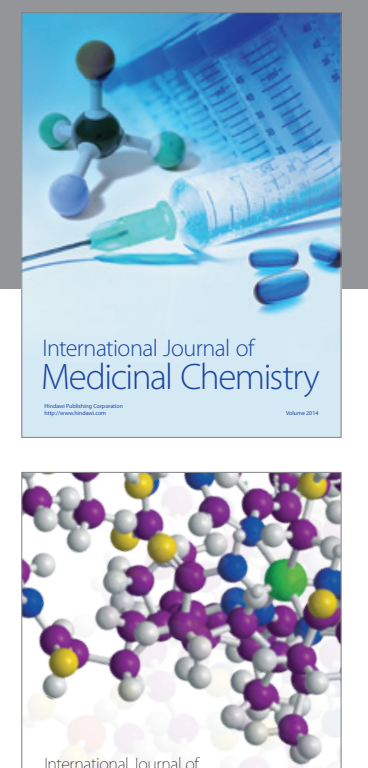

\section{Carbohydrate} Chemistry

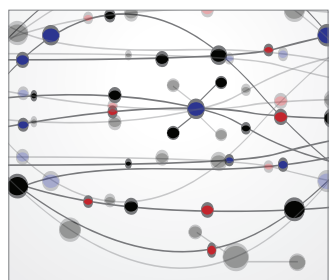

The Scientific World Journal
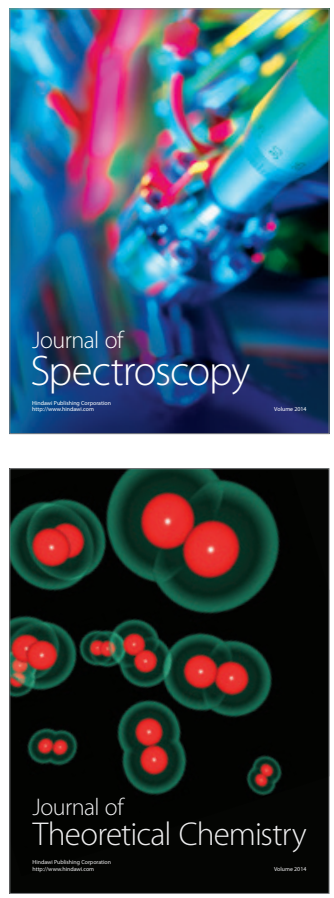
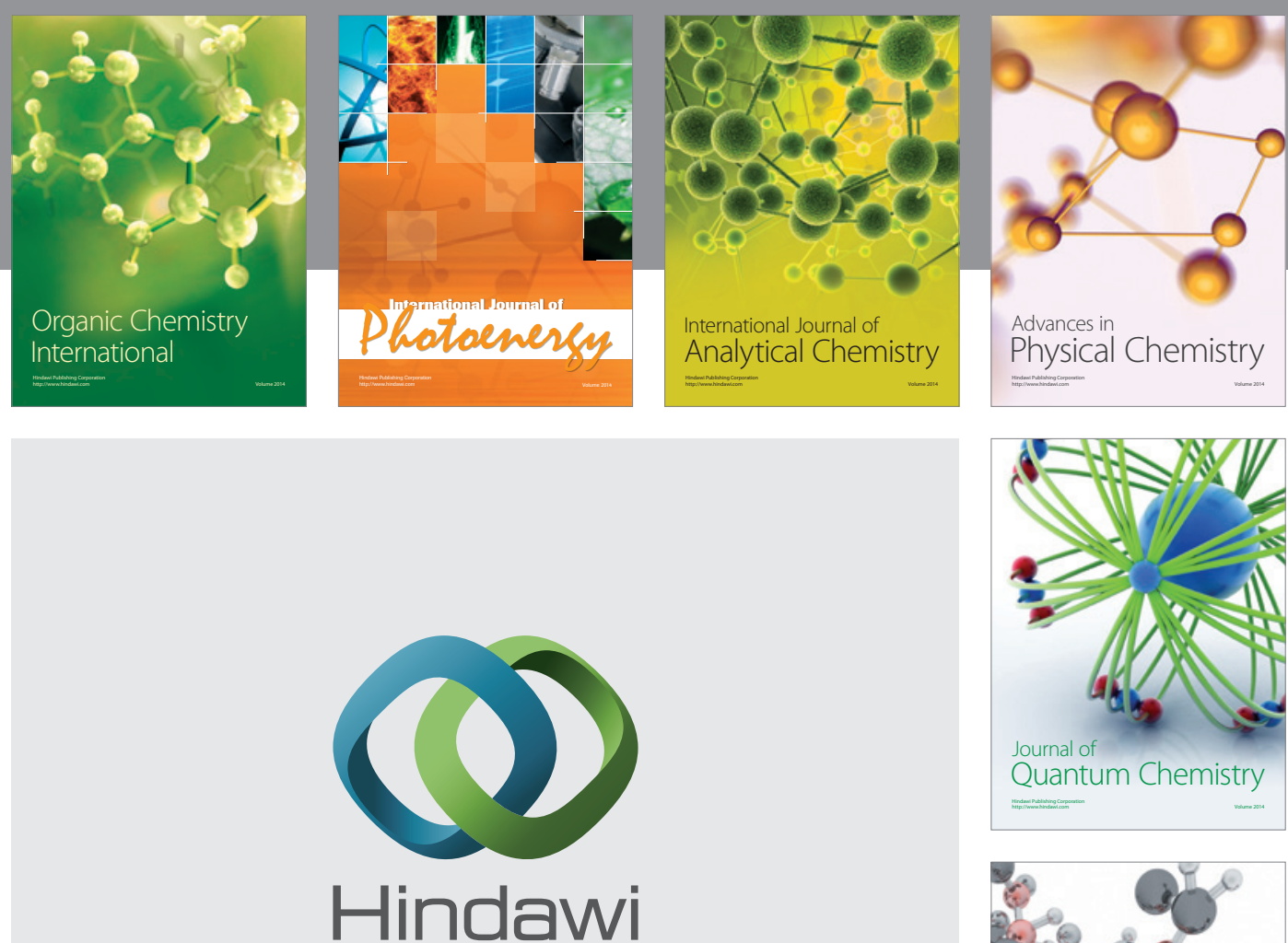

Submit your manuscripts at

http://www.hindawi.com

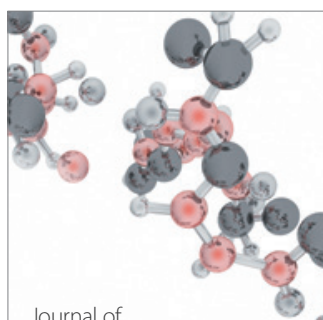

Analytical Methods

in Chemistry

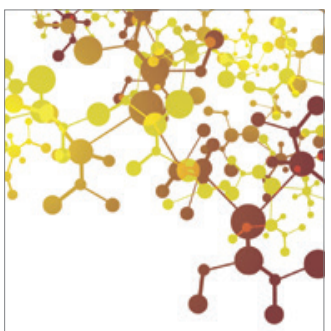

Journal of

Applied Chemistry

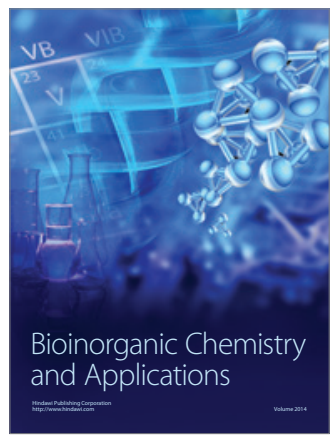

Inorganic Chemistry
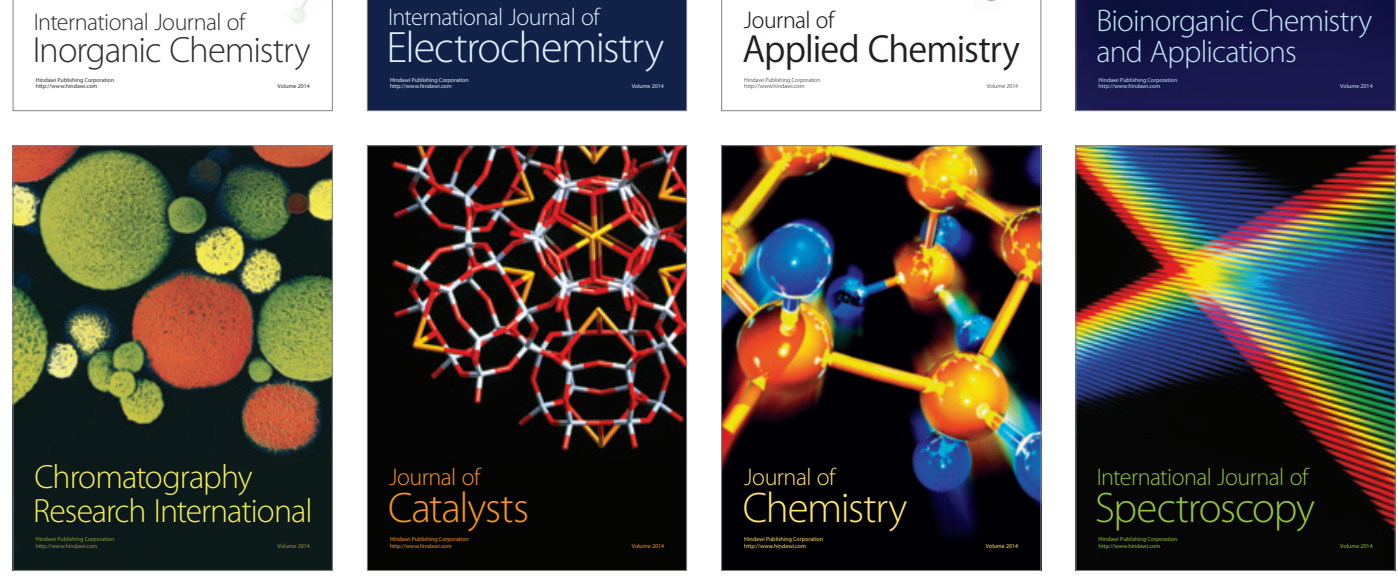